\title{
COLAGENOMA DE CÉLULAS GIGANTES DE CONJUNTIVA BULBAR
}

\section{GIANT CELL COLLAGENOMA OF THE BULBAR CONJUNCTIVA}

\author{
ZARATE JO$^{1}$, PELAYES DE ${ }^{1}$, GIOINO JM ${ }^{1}$, PIANTONI GR ${ }^{1}$
}

\section{RESUMEN}

Objetivo/método: Se presenta un raro tumor con ubicación conjuntival, un colagenoma de células gigantes. Se exponen las características histopatológicas utilizando Hematoxilina y Eosina, PAS, Tricrómico de Masson e inmunohistoquímica.

Resultados/conclusiones: Se presentan las características clínicas e histopatológicas del colagenoma de células gigantes de conjuntiva, que son similares a las características de éste tumor en otras partes del cuerpo. Este es el primer reporte de este tumor en el ojo.

Palabras claves: Conjuntiva, colagenoma, células gigantes, inmunohistoquímica.

\section{INTRODUCCIÓN}

En 1998, un nuevo tumor fibroblástico de partes blandas que se ubican con mayor frecuencia en los miembros inferiores el mismo fue denominado colagenoma de células gigantes por Rudolph (1), dicho tumor se caracteriza por presentar dos componentes:

1. Matriz colágena hialinizada con patrón estoriforme.

\begin{abstract}
Purpose/methods: To report a rare case of a tumor in a conjunctival location, a giant cell collagenoma. Tissue was stained with hematoxylin-eosin, periodic acid-Schiff, and Masson's trichromic stain and studied by immunohistochemistry.

Results/conclusion: The clinical and histopathologic features of conjunctival giant cell collagenoma are similar to characteristics of the same tumor occurring in other parts of the body. This is the first report of this tumor in the eye (Arch Soc Esp Oftalmol 2007; 82: 233-236).
\end{abstract}

Key words: Conjunctiva, collagenoma, giant cell, immunohistochemistry.

2. Presencia de células gigantes.

Se presenta un caso de esta patología con localizado en la conjuntiva bulbar.

\section{CASO CLÍNICO}

Paciente de sexo masculino de 48 años de edad acudió a consulta por presentar una lesión tumoral en el ojo derecho (OD) de 1 año de evolución. La

\footnotetext{
Recibido: 19/1/06. Aceptado: 26/3/07.

II Cátedra de Oftalmología. Departamento de Patología, Universidad de Buenos Aires. Buenos Aires. Argentina.

1 Doctor en Medicina.

Correspondencia:

Jorge O Zarate

Libertad 679 (1770), Aldo Bonzi

Buenos Aires

Argentina

E-mail: zarate@ciudad.com.ar
} 


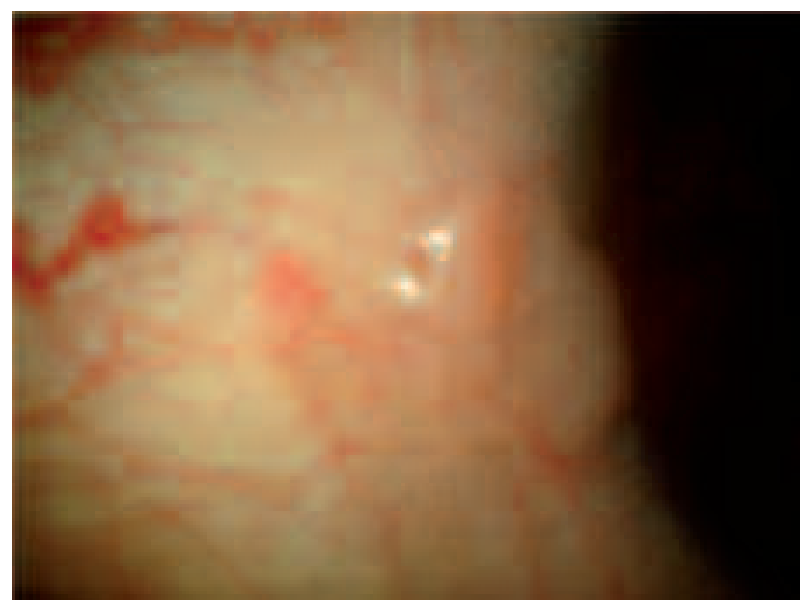

Fig. 1: Características clínicas de la lesión blancanodular en la conjuntiva limbar.

misma era indolora y había presentado un lento crecimiento.

El examen oftalmológico presentó una agudeza visual de 1 en ambos ojos (AO) y en el examen biomicroscópico se observó una lesión sobreelevada, de color blanco-nacarado, con una superficie multinodulada, móvil, dura, ubicada a nivel conjuntivo-limbar entre hora 6 y 7 de OD. La misma se acompañaba de una moderada inyección conjuntival perilesional. El ojo izquierdo (OI) no presentaba alteraciones patológicas. El examen del segmento posterior era normal en AO. La presión intraocular (PIO) era de $12 \mathrm{mmHg}$ en el OD y $14 \mathrm{mmHg}$ en el OI, sin evidencias de linfoadenopatías.

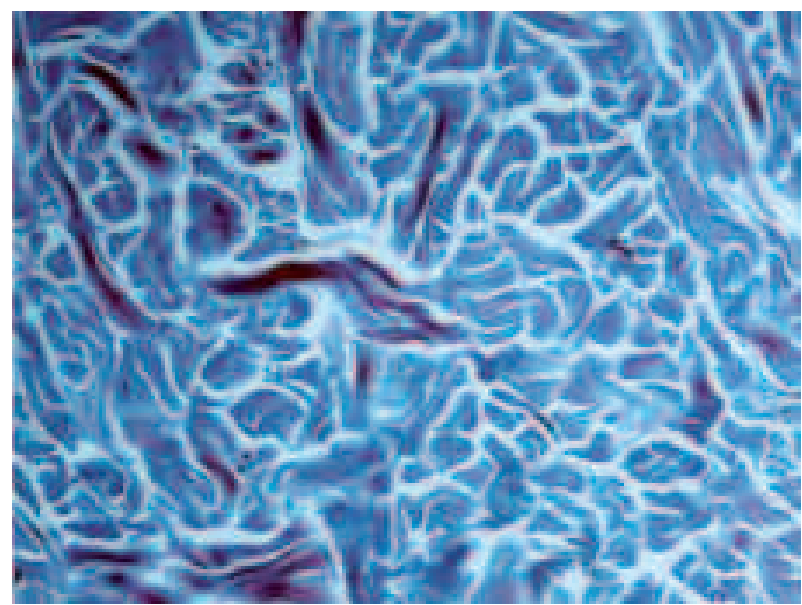

Fig. 2: Patrón estoriforme del estroma hialinizado (Tricrómico de Masson).

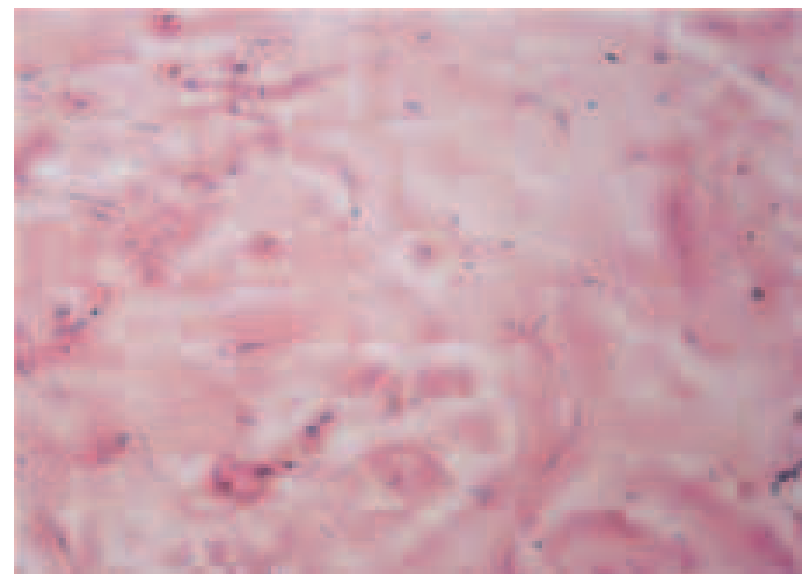

Fig. 3: Células gigantes multinucleadas distribuidas en el estroma.

Se realizó la resección local de la lesión sin complicaciones y posterior biopsia de la misma.

Macroscópicamente se trataba de una lesión circunscripta pero no encapsulada de consistencia firme-elástica con aspecto blanco nacarado homogéneo, sin evidencias de necrosis, hemorragias ni calcificaciones. Dicha lesión medía 0,9 x 0,5 x 0,2 mm.

La muestra se fijó en formol buffer al $10 \%$ para su examen histológico, posterior inclusión en parafina y coloración con Hematoxilina y Eosina, PAS y Tricrómico de Masson. Éstos estudios revelaron que el tumor consistía en una prominente matriz hipocelular compuesta por bandas hialinizadas de colágeno que adoptaban un patrón estoriforme. Entre las mismas se observaron numerosas células gigantes multinucleadas con citoplasma claro, sin

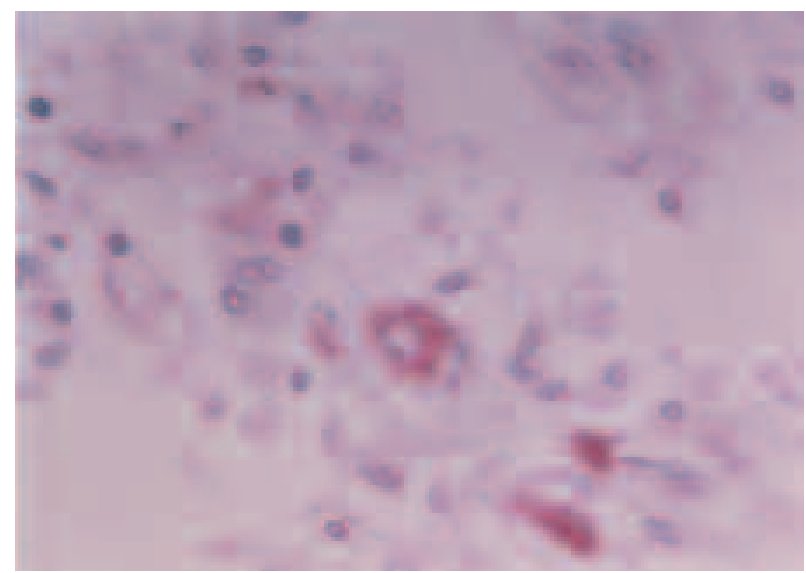

Fig. 4: Expresión de vimentina en células gigantes multinucleadas. 
pleomorfismo o hipercromatismo nuclear, ni evidencia de figuras mitóticas. En adición con éstas células gigantes se observaron células estrelladas con morfología nuclear análoga y distribuidas en forma aislada en el estroma. No se identificaron zonas de necrosis, cambios fibromixoides o calcificaciones.

Posteriormente se llevaron a cabo los estudios de inmunohistoquímica (IHQ) utilizando anticuerpos monoclonales en suero bovino al $1 \%$. Se utilizaron los siguientes anticuerpos: vimentina (BioGenex), citoqueratina (BioGenex), desmina (BioGenex), proteína S-100 (BioGenex), CD34 (BioGenex) y CD68 (Dako). La lesión fue difusamente positiva para vimentina y solamente las células gigantes fueron positiva para CD68 pero negativas para citoqueratina, desmina, proteína S-100 y CD34.

El diagnóstico fue colagenoma de células gigantes de conjuntiva bulbar.

\section{DISCUSIÓN}

El colagenoma de células gigantes es un raro tumor de partes blandas, y se piensas que su origen podrían ser las células fibroblásticas. Rudolph (1) describe esta neoplasia dentro de los tumores fibroblásticos de partes blandas, donde el patrón morfológico determinante lo constituye el intenso depósito de matriz colágena hialinizada con patrón estoriforme y la presencia de células gigantes; este último criterio evaluativo no está presente en todos estos tumores dando paso a que en la nomenclatura se describan como fibroblastoma desmoplástico, fibroma colagenoma, fibroblastoma a células gigantes, etc.

Se han reportado casos de fibroma colagenoso (fibroblastoma desmoplástico) $(2,3)$ en diferentes sitios del cuerpo, siendo las extremidades el lugar de mayor frecuencia. Otros sitios son el cuello, hombro, parótidas, frente y pies. Todos los pacientes se presentaron con una masa indolora y de lento crecimiento. El tumor se presenta con la misma frecuencia en ambos sexos.

El colagenoma estoriforme circunscrito fue mencionado por primera vez por Weary et al (4) hace 31 años atrás en el contexto de la Enfermedad de Cowden, siendo considerado como uno de los principales criterios de diagnóstico del síndrome de hamartoma múltiple. Rapini y Golitz reportaron subsecuentemente una forma esporádica de aspecto aná- logo por lo que Metcalf (5) propuso describirlo de una forma más individual designándolo colagenoma estoriforme circunscrito.

Todos estos tumores mencionados podrían corresponder a un grupo cuya característica es la matriz colagenosa.

La morfología, las características estructurales de la matriz con abundantes depósitos de colágenos y la presencia de células bizarra demuestran la gran similitud de la lesión de éste caso con el tumor denominado por Rudolp como «colagenoma de células gigantes».

En el diagnóstico histológico diferencial se incluyen varias proliferaciones fibrosas con células multinucleadas como el fibroma pleomórfico, variantes de dermatofibroma, fibroxantoma atípico, fibroblastoma de células gigantes, nevo de Spitz, lipoma pleomórfico, reticulohistiocitoma, variantes de xantomas o xantogranulomas y lesiones inflamatorias histiocíticas como reacciones de cuerpo extraño con formación de cicatriz queloidea.

Un punto a tener en cuenta cuando el tumor se ubica en el ojo es que las características oftalmológicas de la lesión, de aspecto blanquecino-nodulada, dura y firmemente adherida a los tejidos, puede ser interpretado como una neoplasia de comportamiento maligno y llevar a errores terapéuticos en estos casos.

A pesar del bazarrísimo celular de las células gigantes, la ausencia de mitosis y la evolución clínica confirmarían la benignidad de esta entidad neoplásica.

En resumen se presenta un caso de colagenoma de células gigantes de la conjuntiva, futuros trabajos con un mayor número de éstos tumores permitirán conocer mejor este tipo de lesiones.

\section{BIBLIOGRAFÍA}

1. Rudolph P, Schubert C, Harms D, Parwaresch R. Giant cell Collagenoma: a benign dermal tumor with distinctive multinucleate cells. Am J Surg Pathol 1998; 22: 557-563.

2. Evans HL. Desmoplastic fibroblastoma. A report of seven cases. Am J Surg Pathol 1995; 19: 1077-1081.

3. Nielsen GP, O'Connell JX, Dickersin GR, Rosenberg AE. Collagenous fibroma (desmoplastic fibroblastoma): a report of seven cases. Mod Pathol 1996; 9: 781-785.

4. Weary PE, Gorlin RJ, Gentry WC Jr, Comer JE, Greer KE. Multiple hamartoma syndrome (Cowden's disease). Arch Dermathol 1972; 106: 682-690.

5. Metcalf JS, Maize JC, LeBoit PE. Circumscribed storiform collagenoma (sclerosing fibroma). Am J Dermatopathol 1991; 13:122-129. 